\title{
Using Time-Lapse Video Photography to Assess Dairy Cattle Lying Behavior in a Free-Stall Barn
}

\author{
M. W. Overton, W. M. Sischo, G. D. Temple, and D. A. Moore \\ Veterinary Medicine Teaching and Research Center, \\ University of California, Davis
}

\begin{abstract}
The objectives of this observational study were to use time-lapse video photography to document dairy cow behavioral patterns, examine factors affecting lying behavior, and to develop guidelines for visual assessment of free-stall usage during summer conditions in a high producing dairy. Four video cameras were placed in a free-stall pen containing 144 stalls and 129 high producing cows. The videos were recorded over a 6 -d period in July 1999 and then were reviewed using 60-min scan sampling techniques. Cows were counted as lying, standing in alley without eating, standing in free stalls, or eating in each of the four sections of the pen. Temperature probes were placed on the feedline, free stalls, on both ends of the pen, and at an outside location. Relationships between proportion eligible lying and ambient temperature, feeding time, and time since milking were examined. Proportion eligible lying was equal to number of cows lying divided by total number of cows lying or standing but not eating. Cattle showed a significant pattern of temporal cyclicity in their lying behavior, with the highest average proportion of eligible cows lying at 6:00 a.m. (85\%) and the lowest at 9:00 p.m. (53\%). Increasing environmental temperatures and time elapsed since milking negatively impacted proportion of eligible cows observed lying when evaluated using 60-min scan sampling techniques.
\end{abstract}

(Key words: cattle behavior, time-lapse video, cow comfort, lying behavior)

Abbreviation key: FS_Temp = average free stall temperature, Milk_Lag = hours post-milking, Push-up = time of feed push-up.

\section{INTRODUCTION}

Applied animal ethology has become an integral part of animal science in the last $40 \mathrm{yr}$, as investigators have

Received November 1, 2001

Accepted April 1, 2002.

Corresponding author: Michael Overton; e-mail: Moverton@ vmtrc.ucdavis.edu. increasingly examined the physical and psychological needs of cattle (Curtis and Houpt, 1983). Ethological studies are more critical than ever as more dairies turn to total confinement free-stall housing in attempts to optimize labor, facilities, and land use and to meet more stringent environmental regulations that require the capture of all wastewater and rainfall that contacts animal waste. Unfortunately, free-stall housing systems are usually designed to maximize stocking density and efficiency for management, but may not adequately address cow comfort, health, and behavioral needs. Greenough and Weaver reviewed the literature and concluded that the increasing incidence of lameness in dairy cattle was most likely associated with housing conditions and intensive management primarily directed at achieving higher milk production (Greenough and Weaver, 1997).

Poorly designed or mismanaged housing facilities, especially total confinement on concrete, can alter normal social interactions, interfere with resting behavior, and promote longer standing times (Greenough and Vermunt, 1991; Singh et al., 1993; Bickert and Cermak, 1997). Stressors such as disturbed rest and uncomfortable resting areas may lead to altered levels of cortisol and increased heart rate in dairy cattle, and may increase the risk of involuntary culling, lower milk production, and reduce reproductive efficiency (Ladewig and Smidt, 1989; Müller et al., 1989).

Despite the importance of cow comfort and rest, assessment of housing systems for cow comfort can be difficult. Researchers have used a variety of time-lapse photography techniques to investigate dairy cattle behavior patterns, free-stall utilization, social interactions, and lameness risk factors (Friend and Polan, 1974; Galindo and Broom, 1993; Menzi and Chase, 1994). These studies usually involve either continuous sampling or scan sampling at intervals of 5 to $15 \mathrm{~min}$ of small groups of cattle (typically 10 to 25 ) to more accurately measure total times spent in various activities such as lying, eating, or standing. Müller et al. (1989) suggested that comparisons between housing systems and evaluations for cow comfort are only reasonable if performed with a sufficient numbers of obser- 
vations or at a set period of time, such as following the morning feeding.

Dairy consultants and veterinarians generally agree that the majority of cows' idle time should be spent lying, but most consultants do not have access to photographic techniques or time for tape review. As a result, many advisors rely on walk-through observations to assess free-stall usage and cow comfort for groups rather than in individual animals. Total proportion lying is an index that is sometimes used, but it fails to account for the impact of time spent eating. Proportion eligible lying or "free-stall-use index" is another measure that adjusts for cows that are eating by excluding them from the calculation. Information regarding walkthrough assessment of free-stall usage is lacking in peer-reviewed literature, but in the lay press, the most commonly used index for evaluating cow comfort is the "cow comfort index" (Roenfeldt, 1995; Michael, 2001). The numerator consists of cows lying in free stalls and the denominator is the total number of cows touching a stall. A value greater than $85 \%$ is considered the desired goal.

Although there is some agreement about the goal for cow comfort, there is no standard for collecting the data and little in peer-reviewed literature to help interpret these single-point observations. Confounding variables such as time of feed delivery, milking times, or ambient temperature at the time of observation will most likely result in different evaluations. The objectives of this observational study were to use time-lapse video photography to document dairy cow behavioral patterns, examine relationships between environment, management activities, and resting behavior using 60 -min scan sampling, and to develop guidelines for making a onetime visual assessment of free-stall usage in freestall dairies.

\section{MATERIALS AND METHODS}

\section{Study Herd}

This observational study was conducted in a $1.5-\mathrm{yr}-$ old, total confinement, free-stall facility that housed approximately 500 milking Holstein-Friesian cows. Cows were milked three times daily and averaged over $11,800 \mathrm{~kg}$ of energy-corrected milk. The free-stall barn housing the milking cows was a four-row, head-to-head design with a center drive-through feed alley and contained four pens under one roof. The roof was $4.3 \mathrm{~m}$ tall at the eves with a 4/12-pitch design and open sides, walls, ends, and center ridge. Pen 1 was selected for observation because it housed the highest producing cows on the dairy, and results from these high cows would be of greater value to the dairy community. This pen contained 144 free stalls, 129 cows, and 140 head- locks through which the cows placed their heads to eat. The free stalls were designed with open front lunge space, cantilever dividers, and a lying surface of $1.2 \mathrm{~m}$ wide by $1.7 \mathrm{~m}$ long. Stalls were bedded to a depth of approximately $15 \mathrm{~cm}$ with sand and were raked and groomed once daily while the cows were away at the mid-day milking. The study pen was located on the southeast corner of the building with east and south walls open to the outside and north and west edges facing other pens. Cows in pen 1 were milked three times daily at 4:00 a.m., 12:00 noon, and 7:45 p.m. Cows exited the pen from the west end and walked less than $100 \mathrm{~m}$ on a concrete alley to the milking parlor that was located on the southeast side of the free-stall barn. Lactating cows on this farm had no access to pasture or exercise lots and total time spent away from the housing pen was limited to 2 to 3 h daily. Large droplet/ low pressure sprinklers and fans equipped with highpressure misters were located over the feed bunk and were used to reduce the effects of summer heat. Lanes were flushed 5 to 8 times daily, and stall beds were raked once daily while cows were being milked. A TMR was delivered once daily onto a flat, concrete feed apron and feed was pushed up 6 times daily. The exact times of each of the aforementioned events were recorded following review of the videotapes.

\section{Video Recording}

Four black-and-white, closed-circuit video cameras were evenly spaced in the pen housing the highestproducing multiparous cows on the dairy (EXXIS Security Systems, models ES450 and ER0024T, Lewisville, TX). The four cameras were placed about $5 \mathrm{~m}$ above the pen floor to allow more complete visualization of the pen. Cameras were linked to a central monitor and video recorder.

Filming began on July 20 and ended on July 28, 1999. (Due to recorder malfunction, data were not recorded on July 25.) The monitor displayed a different camera's view every $20 \mathrm{~s}$ in a sequential, repeating cycle, and the video equipment recorded continuously over a 24 $\mathrm{h}$ period. Barn lights were turned off at approximately 10:30 p.m. and remained off until 2:30 a.m., when feed was pushed up, resulting in approximately $4 \mathrm{~h}$ per day where behavior observations could not be observed.

Videotapes were reviewed by freezing images onscreen to improve accuracy of the cow counts (Snappy Video Snapshot, Play Incorporated, Rancho Cordova, CA). Although images were recorded on film at 3-s intervals, observations were made using hourly scan samples due to the labor-intensive efforts required to review the tapes and our belief that hourly observations would adequately capture lying behavior changes. Videotape 
review included all hourly intervals from 3:00 a.m. to 10:00 p.m. except for 8:00 p.m., when cows were away from the free-stall barn for milking. As a result, 19 hourly observations were recorded for each day of the study. Observations of cow behavior for the other two milking times were recorded immediately before a dairy worker entered the pen to remove the cows for milking and were within 10 to 15 min of the scheduled observation times.

Cows were counted as lying, eating, standing-out, or standing-in a stall in each of the four camera sections of the pen. Lying included only cows that were observed in total lateral or sternal recumbency within the confines of a free stall. Standing-out included cows observed standing or walking in the walkways or alleys but not engaged in eating. A cow was counted as standing-in if she stood with two or more feet touching a stall bed. Eating was defined as actively ingesting feed or water, or standing within $0.6 \mathrm{~m}$ of the feed bunk and oriented toward the feed. The free-stall-use index proportion eligible lying was defined as total number lying in free stalls divided by the total number of cows that were not eating during that time period. Cow comfort index was calculated as number observed lying in stalls divided by the total number either lying or standing in a stall for that time period. Only once was a cow seen lying in the alley, but this occurred between hourly observation times and was not entered into the dataset. The entire video observation period covered 113 hourly time periods. For nine of these periods, no observations were made due to a slight change in milking schedule or camera recording error. To complete the dataset, these missing data points were estimated using the average of the other days' corresponding time points.

Feeding, milking, heat detection, and feed push-up times were noted. Patterns of direct sun exposure present in the free stall barn throughout the day were also monitored. All data were entered into a computerized spreadsheet program (Microsoft Excel, Redmond, WA).

\section{Environmental Monitoring}

Before cameras began recording, temperature probes were placed at the fence-line on both ends of the pen, at the feed bunk, and in the free-stall area approximately one third of the way from each end, and at an outside location to record temperatures at 10-min intervals (Optic StowAway Temp, Onset Computer Corporation, Bourne, MA). The outside probe was located adjacent to the free-stall barn under a calf shed that had no fans or sprinklers and was used to estimate the ambient environmental temperature. The temperature probes had an effective range of -35 to $+75^{\circ} \mathrm{C}$ with an accuracy of $\pm 0.5^{\circ} \mathrm{C}$ at $21^{\circ} \mathrm{C}$, a time accuracy of $\pm 1 \mathrm{~min} /$ wk and a response time of approximately $20 \mathrm{~min}$. Data from the probes were directly downloaded and saved into a computerized database (Microsoft Excel).

\section{Statistical Analyses}

Proportion of eligible cows lying was chosen as the primary outcome for measurement. The initial evaluation of temporal independence of lying behavior used a modification of the Friedman non-parametric analysis of variance (ranks) test (Kendall and Ord, 1990). To establish a standardized baseline for comparing lying behavior between time periods, a centered moving average proportion eligible lying was computed across the entire observation period of the study (Kendall and Ord, 1990). The moving average was calculated using ( $\mathrm{m}+$ 1) data points, where ' $m$ ' corresponded to the 19 hourly observation points per day. The centered moving average was subtracted from each hourly observed proportion eligible lying to arrive at a residual or deviation from expected proportion eligible lying. The residuals were modeled using a least squares general linear model with the independent variables of average free stall temperature (FS Temp), hours post-milking (Milk Lag), and feed push-up time (Push up). Freestall temperature was treated as a continuous variable, and Milk-Lag and Push-up were treated as class variables. For any given 24 -h period, there were three sets of Milk Lags that ranged from 1 to $8 \mathrm{~h}$, with Milk_Lag $=1$, representing $1 \mathrm{~h}$ since the previous milking time and Milk_Lag $=8$, representing the next milking time. Push_up was coded as a binary variable representing whether feed was pushed up to the feed bunk during the observation hour. All 2- and 3-way interactions were evaluated.

\section{RESULTS AND DISCUSSION}

\section{Environmental Data}

Temperatures from the feed bunk, free stall, and fence-line probes of pen 1 were compared to determine whether there were temperature differences within the barn. There were no differences in recorded temperatures between feed bunk and free stall, but there were large differences in temperature between east and west ends of the pen, depending on time of day. Direct sun exposure during the late morning created heating effects that resulted in large swings in daily recorded temperatures that ranged from 13 to $42.8^{\circ} \mathrm{C}$ on the east end. The barn's west end was protected from sun exposure by the adjacent free-stall pen, and maximum daily temperatures in this location only reached $32.5^{\circ} \mathrm{C}$. Average ambient temperature outside the pen ranged 
from 13 to $35^{\circ} \mathrm{C}$, while temperatures recorded at the free stalls ranged from 14.3 to $32.2^{\circ} \mathrm{C}$.

During the study period, management routines remained constant. During all observations, cows were seen leaving the pen within 10 min of the stated milking times, and all cows returned to the free-stall pen within 60 to $75 \mathrm{~min}$ of departure. The management policy was that stalls were normally rebedded once every 7 to 10 $\mathrm{d}$, but this was not observed during the study period. Feeding occurred once daily between 10:38 and 10:45 a.m., and feed was pushed up at approximately 3:00 a.m., 6:00 a.m., 9:00 a.m., 3:00 p.m., 7:00 p.m., and at 10:00 p.m. daily. Feed bunks always contained feed, except for about 30 min before feeding, when the dayold feed was removed before delivery of fresh feed. The tail chalk method was used for heat detection, and cows were checked daily between $6: 20$ and 7:45 a.m. for evidence of prior estrus activity. Breeding via AI was performed by either catching a cow in a free stall or by moving her to the west end of the pen for a short lockup period. Minimal effect on cow behavior was observed while dairy workers were in the pen, with very few cows displaying signs of avoidance behavior and most cows continuing to eat or rest.

The alleys were flushed to remove manure and excess sand using recycled wastewater. Alley flushing was manually controlled, and the frequency was determined by the amount of manure present and by availability of labor. The feed-line alley was flushed 8 times/d on 1- to 7-h intervals. The outside free stall alley was flushed 5 times/d on similar intervals. Flushing of the alleys with wastewater had no noticeable effect on cow behavior.

\section{Lying Behavior}

The mean proportions (and standard deviations) of eligible cows lying at each time period are shown in Figure 1. The highest mean proportion lying (86\% of eligible cows, range 80 to $91 \%$ ) was seen at the $6: 00$ a.m. observation, with the 10:00 p.m. observation slightly lower (81\%, range of 76.5 to $84.5 \%$ ). Both of these time periods coincided with Milk Lag of 2. The Friedman ranks test confirmed a nonrandom cyclicity to lying behavior $(P<0.005)$. Although decreased lying behavior was observed during mid-day, late afternoon, and early evening hours, the cow comfort index averaged $89 \%$ over all observations with a range of 71 to $100 \%$.

Our findings of increased resting in the early morning hours are supported by circadian cycle research investigating sleeping habits and resting needs of cattle (Ruckebusch, 1972). Other researchers have found that confined cattle and calves demonstrate greatest synchrony

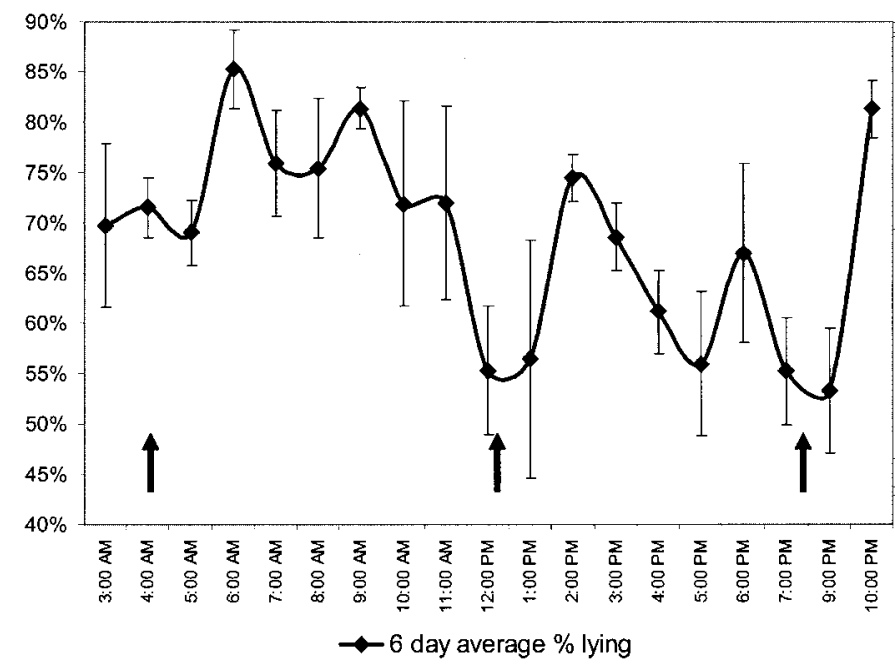

Figure 1. Average proportion of eligible cows observed lying at each observation period (with one-standard deviation error bars) over a 6-d study period. Bold arrows indicate times at which the cows left the barn for milking. Cows left at 4:00 a.m., 12:00 p.m., and 7:45 p.m. for each of the three milkings and returned within one hour.

of lying behavior during the hours around sunrise (O'Connell et al., 1989; Miller and Wood-Gush, 1991). Kondo et al. (1984) used scan sampling techniques to investigate behavior and activities in pen-housed calves and found a tendency for regular, diurnal, synchronized lying patterns based on proportion lying at each hour. If facilities have enough comfortable resting locations, cows are expected to spend a greater proportion of time lying down at night or during the very early morning hours unless otherwise preoccupied by feeding, milking, or management disruptions. During our observations, over $65 \%$ of cows were lying during the hours of 3:00 a.m. to 9:00 a.m., with the exception of the 5:00 a.m. observation period (1-h post milking). During these same hours, fewer than $20 \%$ of cows, on average, were seen feeding, except for the 5:00 a.m. period, where $41 \%$ were eating.

The daily observation period with the lowest average proportion of eligible lying was 9:00 p.m. At this time, an average of 53\% of eligible cows was observed lying (range 45.9 to $63.3 \%$ ). Other times that had similarly low proportion eligible lying were 12:00 p.m., 1:00 p.m., and 7:00 p.m.

As demonstrated in the multivariate model (Table 1), two co-variates were associated with decreased lying behavior. Milk_Lag, and FS_Temp were significant independent influences of lying behavior $(P<0.05)$, but no interaction terms were significant. Although there were 113 time-period observations included in the study, only 94 observations were included in the analyses because the centered moving average could not be 
Table 1. The effect of free stall ambient temperature (FS_Temp) and time from milking (Milk lag) on lying behavior in Holstein dairy cows. Free stall temperature was treated as a continuous variable and Milk-lag was treated as a class variable, where predicted residual proportion eligible lying $=\beta 0+\beta 1($ Milk_Lag) + $\beta 2($ FS_Temp $)+\beta 3$ (Milk_Lag X FS_Temp). ${ }^{1}$ The interaction terms were not significant.

\begin{tabular}{lll}
\hline Variable & $\begin{array}{l}\text { Estimated } \\
\text { effect }(\beta)\end{array}$ & $\begin{array}{l}\text { 90\% Confidence } \\
\text { interval }\end{array}$ \\
\hline Free-stall temperature $^{2}$ & -0.006 & -0.008 to $(-0.005)$ \\
Milk lag 1 $^{3}$ & -0.12 & -0.37 to $(-0.60)$ \\
Milk lag 2 & 0.09 & 0.04 to 0.14 \\
Milk lag 3 & 0.02 & -0.03 to 0.08 \\
Milk lag 4 & Reference & \\
Milk lag 5 & 0.002 & -0.05 to 0.06 \\
Milk lag 6 & 0.04 & -0.02 to 0.09 \\
Milk lag 7 & -0.04 & -0.09 to 0.01 \\
Milk lag 8 & -0.08 & -0.14 to $(-0.02)$ \\
\hline
\end{tabular}

${ }^{1}$ The model $\mathrm{F}$-value $=15.6, P<0.001, \mathrm{df}=93$.

${ }^{2}$ Average temperature at two points within the free-stall barn.

${ }^{3}$ Time from previous milking on hourly intervals ( 1 to $8 \mathrm{~h}$ ).

computed for the first 10 and last 9 recorded observations.

Milk_Lag 1 corresponded to $1 \mathrm{~h}$ after the cows left for milking and had the lowest eligible proportion lying $(59.6 \%$, range of 37.5 to $71.8 \%)$ and the highest proportion eating (52.3\%, range of 41.1 to 59.9\%). Our expectation, based on work by Vasilatos and Wangsness, was that feeding behavior would peak at the observation period immediately following feed delivery (11:00 a.m.) (Vasilatos and Wangsness, 1980). However, the postfeeding period resulted in slightly lower proportion eating (50.0\%, range of 42.7 to $52.5 \%$ ) than the Milk_Lag 1 periods. Our finding of greater feeding activity at Milk_Lag 1 is supported by work from Tyler et al. $(1997,1998)$ who found that cows with feed available upon return from milking spent more time eating and delayed lying until after eating.

The Milk_Lag 1 observation often did not include all of the animals in the pen because the total time required for milking was approximately $60 \mathrm{~min}$, and some cows returned to the pen more slowly than others. While the vast majority of cows that had returned from the milking parlor were observed eating, others that were observed walking down the feed lane after returning from the parlor were recorded as standing, and thus, contributed to the low proportion eligible lying.

Milk_Lag 2 (2 h post milking) was associated with the greatest average proportion of eligible cows lying (80.3\%, range of 70.4 to $90.7 \%$ ). Figure 1 shows three periods of relatively large increases in proportions eligible lying. Each of the three peaks is associated with Milk_Lag 2. These increases were likely a result of synchronization associated with milking, followed by group feeding behavior. The size of the error bars at each observation period in Figure 1 suggests relatively low variation in proportion lying at Milk_Lag 2, but more variation as the observation time moves further away from the previous synchronizing event. Similarly, Miller and Wood-Gush reported that having feed available for cows upon return from milking leads to group feeding behavior and more cows standing for the next 30 to 60 min (Miller and Wood-Gush, 1991). Immediately following the synchronized feeding and standing, more cows may be observed resting.

Milk_Lag periods 7 and 8, which correspond to the 2-h preceding milking, were also low in proportions of eligible cows lying. Those lag periods are expected to be less affected by the synchronization effect observed for Milk_Lag 1 and 2 due to the longer time elapsed since the synchronizing event. In free-stall housing systems, more individualized behavior relative to free-stall use is expected, and cows that have higher needs for feed intake (high milk producers) or cows that have not had equal access to feed (subordinate cows) may return to the bunk for more feed (Arave and Albright, 1981). In addition, increasing intramammary pressure and anticipation of milking may cause cows to stand or move toward the exit gate (Osterman and Redbo, I, 2001).

Environmental temperatures also influenced proportion eligible lying. As shown in Figure 2, lying proportion decreased as pen temperatures increased. The highest mean proportion lying (86\%) was observed during the lowest recorded temperatures $\left(58.8^{\circ} \mathrm{F}\right)$. Despite the presence of fans and sprinklers, the combination of radiant heat effects from the sun on the east end and rising ambient temperatures created higher temperatures within the pen. Shultz has shown that percentage of cows standing increases as environmental temperatures increase (Shultz, 1984). This standing response maximizes evaporative cooling from body surfaces (Igono et al., 1987). Cows in the current study had access to fans and sprinklers that were located over the 


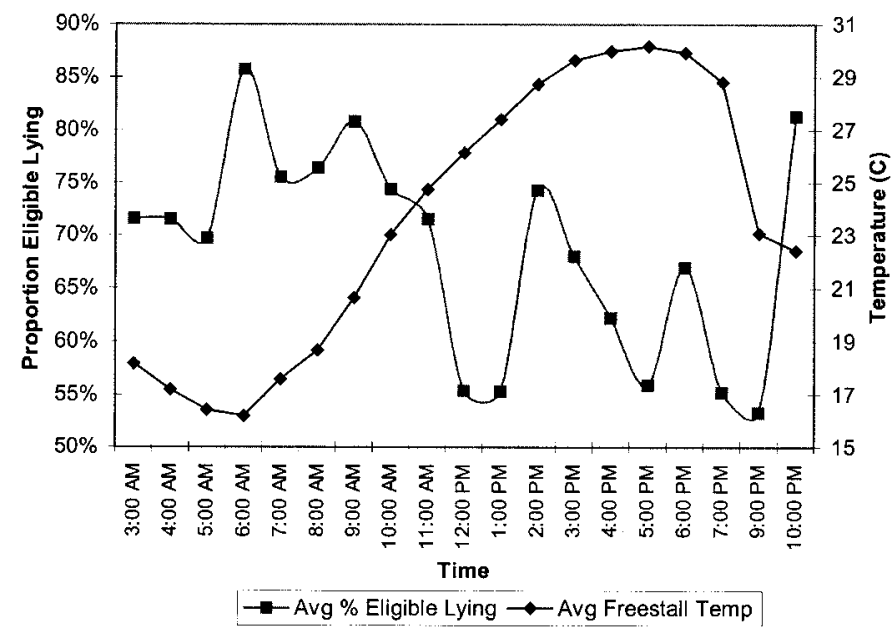

Figure 2. Average proportion of eligible cows observed lying and average ambient temperature $\left({ }^{\circ} \mathrm{C}\right)$ for each of the observation periods over the 6 -d study.

feedbunk, but no cooling was directed over the free stalls. In response to increasing environmental temperatures, some cows in our study may have stood in the feedbunk area to dissipate heat.

The delivery of fresh feed resulted in a larger proportion of cows eating, but feed push-up had no noticeable effect. However, neither feed manipulation event had any effect on lying behavior. Our expectation was that feed delivery would indirectly improve proportion eligible lying by encouraging more standing cows to eat and, thus, change the denominator for proportion eligible lying. In the current study, feeding activity at the observation period immediately following delivery of fresh feed around 10:45 a.m. was slightly lower than those periods immediately following milking (Milk_Lag 1 periods). Our inability to detect any effect of feed manipulation on lying or feeding behavior is most likely due to the constant availability of feed in the manger and the excellent management of the free stalls, which resulted in relatively little idle standing.

The results from this study should be interpreted with caution. Under different management or environmental conditions, optimum times for observation may be different. Limiting access to feed bunks or free stalls by prolonged lock-ups, overcrowding, poor free-stall design, or very slow milk parlor throughput may alter resting behavior. Metz found that deprivation of lying and eating for 3 to $5 \mathrm{~h}$ led to compensatory lying during the subsequent time periods (Metz, 1985). Type of housing system, bedding, and stall design may significantly alter time spent lying or standing and proportion of animals observed lying at any given observation (Haley et al., 2000; Horning and Tost, 2001). Obstacles within a pen may compromise freedom of movement and alter feeding and lying behaviors and increase idle standing (Metz-Stefanowska et al., 1993).

On this dairy, stocking density and free-stall design were not considered as problems. However, visual appraisal of lying behavior using proportions of cows eligible lying or free-stall-use index could still lead to extremely variable conclusions about cow comfort depending on time, since milking and environmental temperature at the time of the observation. During one day, the dairy may have been commended (91\% eligible lying at 6:00 a.m.) or reprimanded (38\% eligible lying at 1:00 p.m.). Under the studied herd's conditions, the optimum time for assessment was at the early morning Milk_Lag 1 period. However, if cow comfort index were used, the results would have been much less variable. On this dairy, the free-stall use index varied from 71 to $100 \%$, with an average of $89 \%$. While both indices have merit, the cow comfort index was much less susceptible to management or temperature effects and would have reported similar findings at any of the three Milk_Lag 1 periods.

Scan sampling with time-lapse video photography provides many benefits compared with one-time, walkthrough appraisals, but it also has certain limitations. Mitlöhner et al. (2001) compared continuous behavioral sampling with scan sampling using intervals of 1,5 , $10,15,30$, and $60 \mathrm{~min}$ and found that for feedlot cattle, scan sampling using very short intervals was highly correlated with continuous sampling for all studied behaviors (Mitlöhner et al., 2001). They found that long interval scan sampling (using 30 to 60 min between scans) was generally inaccurate and imprecise for measuring behaviors of short durations such as eating and drinking but was suitable for estimating lying behavior of feedlot cattle. Therefore, the techniques employed in the current study were probably inadequate to estimate time budgets accurately for short-term activities such as eating or drinking.

\section{CONCLUSIONS}

Time-lapse video photography and scan sampling are valuable tools for investigating dairy cow behavioral patterns. Lying and feeding activities may be recorded without concern of disruption by the presence of an observer. Building orientation may have significant effects on daily temperature changes, due largely to morning and afternoon sun exposure. In the current study, the east end of the free-stall barn was exposed to direct morning sun and experienced a more rapid rise in temperature than other portions of the pen. Extending the roofline or providing shade fabric or curtains on the exposed pen ends during certain times of 
the day might mitigate those effects. Despite having more well-bedded sand free stalls than the number of cows and having a fan and sprinkler cooling system, increasing environmental temperatures significantly decreased proportion lying. Management procedures with the cattle such as feed delivery and push-up, insemination, and milking occurred at very consistent times throughout the study period and influenced behavioral patterns primarily by synchronizing group feeding behavior following return from milking. During hot weather conditions, time elapsed from milking and temperatures within the pen were significant predictors of lying behavior. The highest average proportion of eligible cows lying was $2 \mathrm{~h}$ after cows left for the early morning milking, with the lowest proportion lying found $1 \mathrm{~h}$ after the afternoon and evening milkings. Further study is needed to determine whether these same co-variates are significant during other times of the year and under other dairy management schemes. Individuals evaluating free-stall barns using one-time visual assessments for cow comfort should carefully consider the impact of farm management interactions (especially time since milking) and environmental temperatures. On the farm studied, time-lapse videophotography and 60-min scan sampling suggested that optimum time for walk-through appraisal of maximum proportion lying should be approximately $1 \mathrm{~h}$ after cows return from the early morning milking.

\section{REFERENCES}

Arave, C. W., and J. L. Albright. 1981. Cattle behavior. J. Dairy Sci. 64:1318-1329.

Bickert, W. G., and J. Cermak. 1997. Pages 300-307 in Lameness of Cattle. 3rd ed. W. B. Saunders Co., Philadelphia.

Curtis, S. E., and K. A. Houpt. 1983. Animal ethology: Its emergence in animal science. J. Anim. Sci. 57:234-247.

Friend, T. H., and C. E. Polan. 1974. Social rank, feeding behavior, and free stall utilization by dairy cattle. J. Dairy Sc. 57:12141220 .

Galindo, F. A., and D. M. Broom. 1993. The relationships between social behavior of dairy cows and the occurrence of lameness. Cattle Pract. BCVA 1:360-365.

Greenough, P. R., and J. J. Vermunt. 1991. Evaluation of subclinical laminitis in a dairy herd and observations on associated nutritional and management factors. Vet. Rec. 128:11-17.

Greenough, P. R., and A. D. Weaver. 1997. Lameness of Cattle. 3rd ed. W. B. Saunders Company, Philadelphia.

Haley, D. B., J. Rushen, and A. M. De Passille. 2000. Behavioural indicators of cow comfort: Activity and resting behaviour of dairy cows in two types of housing. Can. J. Anim. Sci. 80(2):257-263.
Horning, B., and J. Tost. 2001. Lying behaviour of dairy cows in different loose housing systems. Polish Committee of Agricultural Engineering. Proceedings of the International Symposium of the C.I.G.R. 2nd Technical Section, 229-237.

Igono, M. O., H. D. Johnson, B. J. Steevens, G. F. Krause, and M. D. Shanklin. 1987. Physiological, productive, and economic benefits of shade, spray, and fan system versus shade for Holstein cows during summer heat. J. Dairy Sci. 70:1069-1079.

Kendall, M., and J. K. Ord. 1990. Time Series. Halstead Press, New York.

Kondo, S., N. Kawakami, H. Kohama, and S. Nushino. 1984. Changes in activity, spatial pattern, and social behavior in calves after grouping. Appl. Anim. Ethol. 11:217-228.

Ladewig, J., and D. Smidt. 1989. Behavior, episodic secretion of cortisol, and adrenocortical reactivity in bulls subjected to tethering. Horm. Behav. 23:344-360.

Menzi, W., Jr., and L. E. Chase. 1994. Feeding behavior of cows housed in free stall barns. Pages 829-833 in Proc. 3rd International Dairy Housing Conference, Am. Soc. Agric. Eng. St. Joseph, MI.

Metz-Stefanowska, J., A. H. Ipema, C. C. Ketelaar-de Lauwere, and E. Benders. 1993. Feeding and drinking strategy of dairy cows after the introduction of one-way traffic into the loose housing system, in the context of automatic milking. Pages 319-329 in Livestock Environment IV, Fourth International Symposium, Coventry, England.

Metz, J. H. 1985. The reaction of cows to a short-term deprivation of lying. Appl. Anim. Behav. Sci. 13:301-307.

Michael, N. 2001. Effects of cow comfort on reproduction. W. Dairy Bus. April, 8-11.

Miller, K., and D. G. Wood-Gush. 1991. Some effects of housing on the social behaviour of dairy cows. Anim. Prod. 53:271-278.

Mitlohner, F. M., J. L. Morrow-Tesch, S. C. Wilson, J. W. Dailey, and J. J. McGlone. 2001. Behavioral sampling techniques for feedlot cattle. J. Anim Sci. 79:1189-1193.

Müller, C., J. Ladewig, H. H. Thielscher, and D. Smidt. 1989. Behavior and heart rate of heifers housed in tether stanchions without straw. Physiol Behav. 46:751-754.

O'Connell, J., P. S. Giller, and W. Meaney. 1989. A comparison of dairy cattle behavioural patterns at pasture and during confinement. Irish J. Agric. Res. 28:65-72.

Osterman, S., and I. Redbo. 2001. Effects of milking frequency on lying down and getting up behaviour in dairy cows. Appl. Anim Behav. Sci. 70:167-176.

Roenfeldt, S. 1995. Rate your cow's comfort. Dairy Herd Mgmt. February $8-10$.

Ruckebusch, Y. 1972. The relevance of drowsiness in the circadian cycle of farm animals. Anim. Behav. 20:637-643.

Shultz, T. A. 1984. Weather and shade effects on cow corral activities. J. Dairy Sci. 67:868-873.

Singh, S. S., W. R. Ward, K. Lautenbach, J. W. Hughes, and R. D. Murray. 1993. Behavior of first lactation and adult dairy cows while housed and at pasture and its relationship with sole lesions. Vet. Rec. 133:469-474.

Tyler, J. W., L. K. Fox, S. M. Parish, J. Swain, D. L. Johnson, H. A. Grasseschi, and R. Gant. 1997. Effect of feed availability on postmilking standing time in dairy cows. J. Dairy Res. 64:617-620.

Tyler, J. W., B. J. Steevens, J. M. Holle, S. M. Croucher, and K. L. Anderson. 1998. Modification of postmilking standing time by altering feed availability. J. Dairy Res. 65:681-683.

Vasilatos, R., and P. J. Wangsness. 1980. Feeding behavior of lactating dairy cows as measured by time-lapse photography. J. Dairy Sci. 63:412-416. 